\title{
Review
}

\section{Processing Strategies for Resource Conservation and Environmental Protection}

\author{
by
}

\author{
T. S. Jordan ${ }^{\dagger}$
}

\begin{abstract}
Reexamination of the traditional status of metal/mineral processing engineering points to an increasing need for process development efforts to place greater emphasis on environmental concerns, both in terms of conserving the Earth's finite natural resources and in protecting the environment. This paper reviews some processes which exemplify thorough utilization of raw materials.
\end{abstract}

Key Words : processing strategy, resource conservation, environmental protection, mineral processing, metal processing

\section{INTRODUCTION}

In keeping with ICMR '91 Akita's purpose of reexamining the traditional status of engineering fields, it would appear that the most significant change emerging in the area of mineral and metal processing is the reshaping of processing economics resulting from environmental concerns. While future improvements in equipment and technology, especially in process instrumentation and control, can be expected, it is doubtful that any new technology will have as great an effect on processing strategy as will the need to rethink process economics in the light of environmental preservation.

In the treatment of ores, there is a point at which increased recovery of any component may cost more than the value of the material recovered. Traditionally, plant practice has been to process only to this "point of diminishing returns", leaving the remaining material in the tailings. This has resulted in the rejection of staggering quantities of partially depleted mineral resources. Often, as techologies and economics have changed, these resources have been reprocessed for mineral recovery, producing a leaner tailing which still contained that fraction of the minerals whose value was less than its recovery cost. Many such tailing deposits contain toxic elements, which may react with the elements to produce contaminated groundwater harmful to animal, plant and aquatic life.

Increasing environmental awareness is bringing about regulations which drastically limit the allowable discharge of toxic elements from new and existing plants and assign liability for remediation of old and abandoned mineral processing sites. Processes of the future will require recovery of minerals to an extent at which the ecomomic incentive will be not merely the value of minerals, but 
also the avoidance of fines or enclosed closure. Thus, future operations will strive for more complete recovery of the major constisuents and for co-recovery of by-products, even though their production costs may exceed their value or they may not be marktable and require storage or costly disposal.

Past practice has seen many operations which, for various reasons, sought to attain unusually complete utilization of the components associated with the natural resources being treated. The operations that will be reviewed here do not exemplify widespread practice, nor are they especially novel. Rather, they are technically viable systems adapted to suit some particular conditions. Future circumstances are likely to encourage adaptation of similar processes. As Madigan has pointed out, "Technological innovation includes the introduction of old ideas to new processes or in new circumstances".

\section{INDUSTRY STRATEGIES}

\section{1 INDUSTRIES BASED ON UTILIZATION OF RECYCLE STREAMS}

\section{1. 1 THE LAKESHORE PROCESS}

Hecla Mining Company began operation of its Lakeshore copper property in Pinal County, Arizona in 1976. By the time this property had been discovered, environmental awareness was such that the criteria put forth by the company for process selection included the requirement that the treatment processes must not only meet environmental standards existing at that time, but must be adaptable to more stringent restrictions that might be imposed at a later date. ${ }^{2}$

Lakeshore mineralization consisted of both oxide and sulfide orebodies. Thus, it was practical to pursue a treatment scheme in which sulfuric acid for leaching the oxides would be produced by roasting sulfide flotation concentrates. The Roast-Leach-Electrowin process, which had found prior application in Arizona, Zambia and Zaire, was selected. Not only did this process recover copper in a liquor of sufficient purity for the production of high quality copper cathodes without going through solvent extractiom, it also produced sulfur dioxide gas suitable for conversion to sulfuric acid. With close temperature control, readily attainable in fluid bed roasting, about $97 \%$ of the copper could be solubilized without taking excessive iron into solution.

Pregnant copper solution from the roast-leach operation was reduced from $55 \mathrm{~g} / 1$ to $15 \mathrm{~g} / 1 \mathrm{Cu}$ by electrowinning and the spent electrolyte, containing about $75 \mathrm{~g} / 1$ acid, was utilized along with fresh $\mathrm{H}_{2} \mathrm{SO}_{4}$ from the acid plant in leaching oxide ore. Liquors from leaching the oxides, which was done by percolation in vats, were not pure enough for direct electrowinning, so the copper was recovered by cementation with sponge iron.

Residue from the roast-leach operation ; primarily iron oxides but containing some gold and silver, whatever copper had not been dissolved in the leach plus considerable waste from gangue in the flotion concentrate; was converted to sponge iron by direct reduction with coal via the SLRN process.

While this sponge would not be acceptable to a blast furnace operator, it was well metallized and porous, making an ideal precipitant. Further ; since it contained copper, gold and silver ; recovery of these elements from the flotation concentrates was complete.

The Lakeshore flowsheet is outlined in Figure $1 .^{3}$ While it may appear complex, each of the operations was well proven in prior practice. Ample allowance for the interdependence of the various units was easily provided. Magnetite was recovered from concentrator tailing for iron makeup in case the amount contained in roast-leach residue should prove insufficient. The sponge iron plant 
was built with a large design factor, since this was the least proven of the processes and thus likely to have the least availability. Finally, facilities for sulfuric acid storage were provided so that acid could be purchased for a shortfall or sold when production exceeded consumption.

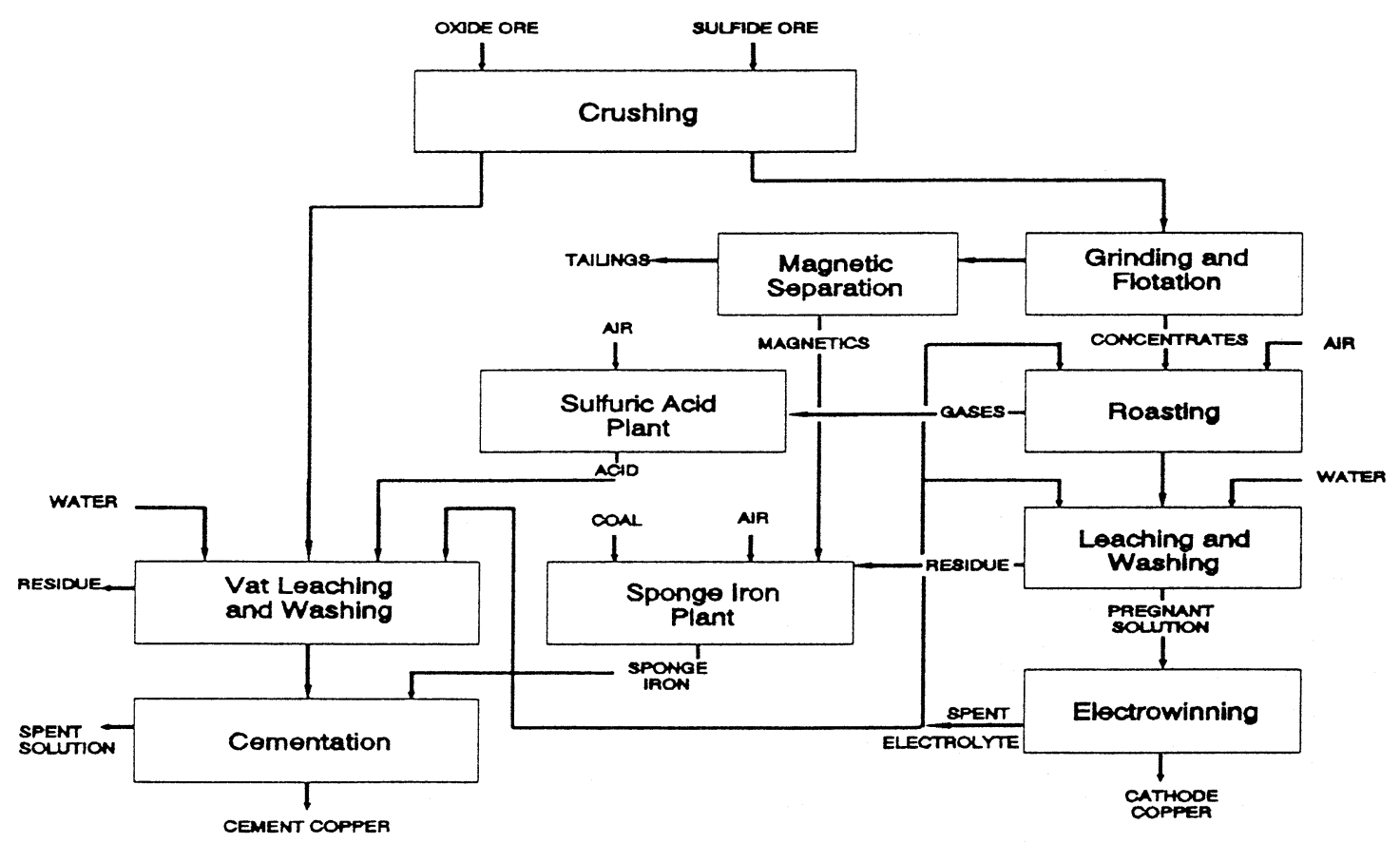

Figure. 1 The Lakeshore Flowsheet

\section{1. 2 ASARCO INTER-PLANT MATERIAL FLOWS}

ASARCO Incorporated is one of the world's major producers of lead, zinc, copper, silver and gold. Through the years they have developed a system of inter-plant transfer of materials for recovery of contained metals. For example, slag and baghouse dust from their Amarillo copper refinery are shipped to a lead smelter and residues are recycled to a copper smelter ; speiss from a lead smelter goes to a copper smelter; their cadmium plant produces test lead, litharge and zinc carbonate byproducts and ships residues to the appropriate lead and copper smelters; et cetera. Material flows between the various plantr are diagrammed in Figure $2 .{ }^{4}$

\section{2 INDUSTRIES BASED ON UTILIZATION OF PYRITE CINDER}

\section{2. 1 THE DUISBURGER KUPFERHUTTE}

This company was founded in 1876 to purchase pyrites for ten chemical plants in Germany's Rhine valley and to process the cinder resulting from sulfuric acid manufacture for recovery of the metals they contained. At that time, the cinders were rich in copper, which accounts for the "kupfer" in the company name. ${ }^{5}$

The founders of Duisburger Kupferhutte (DK) were involved in the manufacture of sulfuric and as a group purchased large quantities of iron pyrite from Europe and the Americas. This resulted in the generation of pyrite cinder which grew to about 2 million tons per year by the 1970's. The 
cinders shipped to DK had a typical analysis shown in Table $1 .^{6}$

Virtually all of the above elements were recovered as marketable products through a process that began with a chloridizing roast of the cinder. As would be expected, the process was varied throughout the long history of the company. A general outline of the flowsheet is presented in Figure 3.

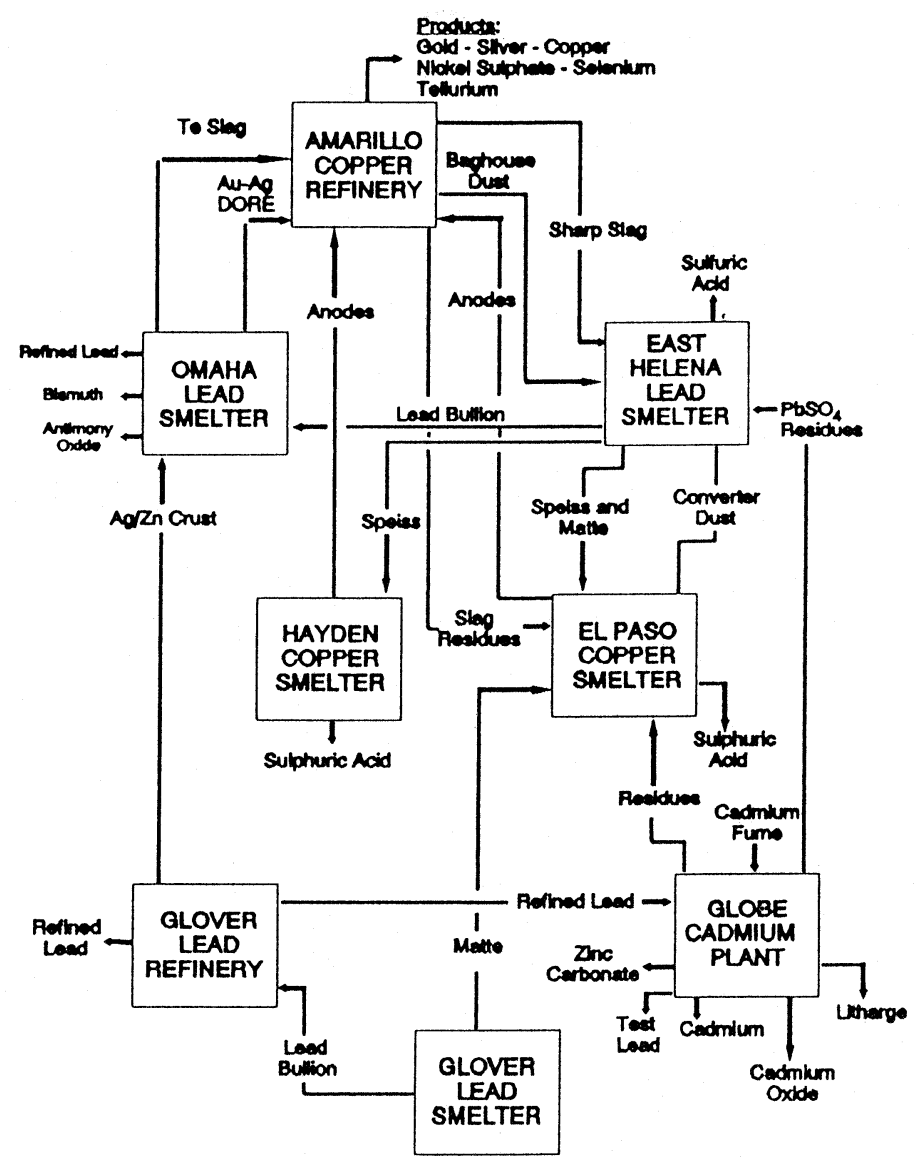

Figure. 2 ASARCO Inter-Plant Material Flows

Table 1 Typical Analysis of DK Plant Feed

\begin{tabular}{lrll}
\hline Element & \multicolumn{1}{c}{} & Element & $\underline{\mathrm{PPM}}$ \\
Iron & $56.0-58.0$ & Cobalt & $300-1500$ \\
Suleur & $2.5-4.0$ & Nickel & $10-1500$ \\
Copper & $0.8-1.5$ & Manganese & $300-3000$ \\
Zinc & $2.0-3.2$ & Silver & $25-50$ \\
Lead & $0.3-0.5$ & Gold & $0.5-1.0$ \\
Ganfue & $6.0-10.0$ & Cadmium & $40-100$ \\
& & Thallium & $15-45$ \\
& & Indium & $1-50$ \\
& & Platinum & about 0.01 \\
\hline
\end{tabular}




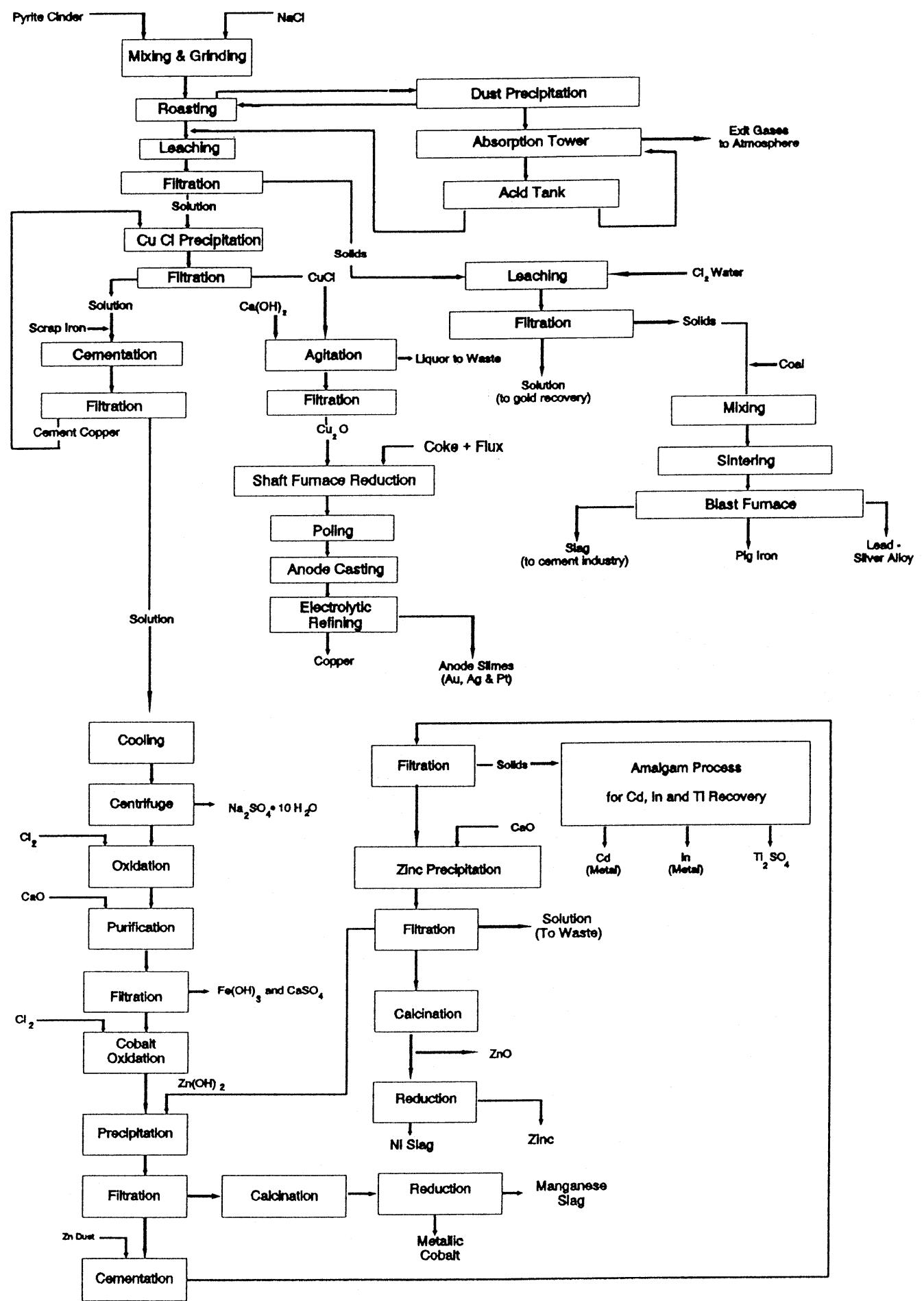

Figure. 3 Duisburger Kupferhutte Flowsheet 


\section{2. 2 THE MONTECATINI PLANT}

The Montecatini plant, near Fallonica, Grosetto, Italy, also used pyrite as a starting material. The pyrite was roasted to produce sulfuric acid and heat, which was captured in waste heat boilers for power generation by the parent company, Montedison SPA. The pyrite cinder, primarily artificial hematite, was reduced to magnetite with fuel oil in fluid bed roasters. The cooled product was then concentrated by conventional magnetic separation followed by pelletizing on a horizontal grate furnace to produce blast furnace feed. From 2000-2100 tonnes per day of concentrate analyzing $38 \%$ iron and $38 \%$ sulfur, the plant produced $2200 \mathrm{mtpd}$ sulfuric acid, $1100 \mathrm{mtpd}$ iron oxide pellets and

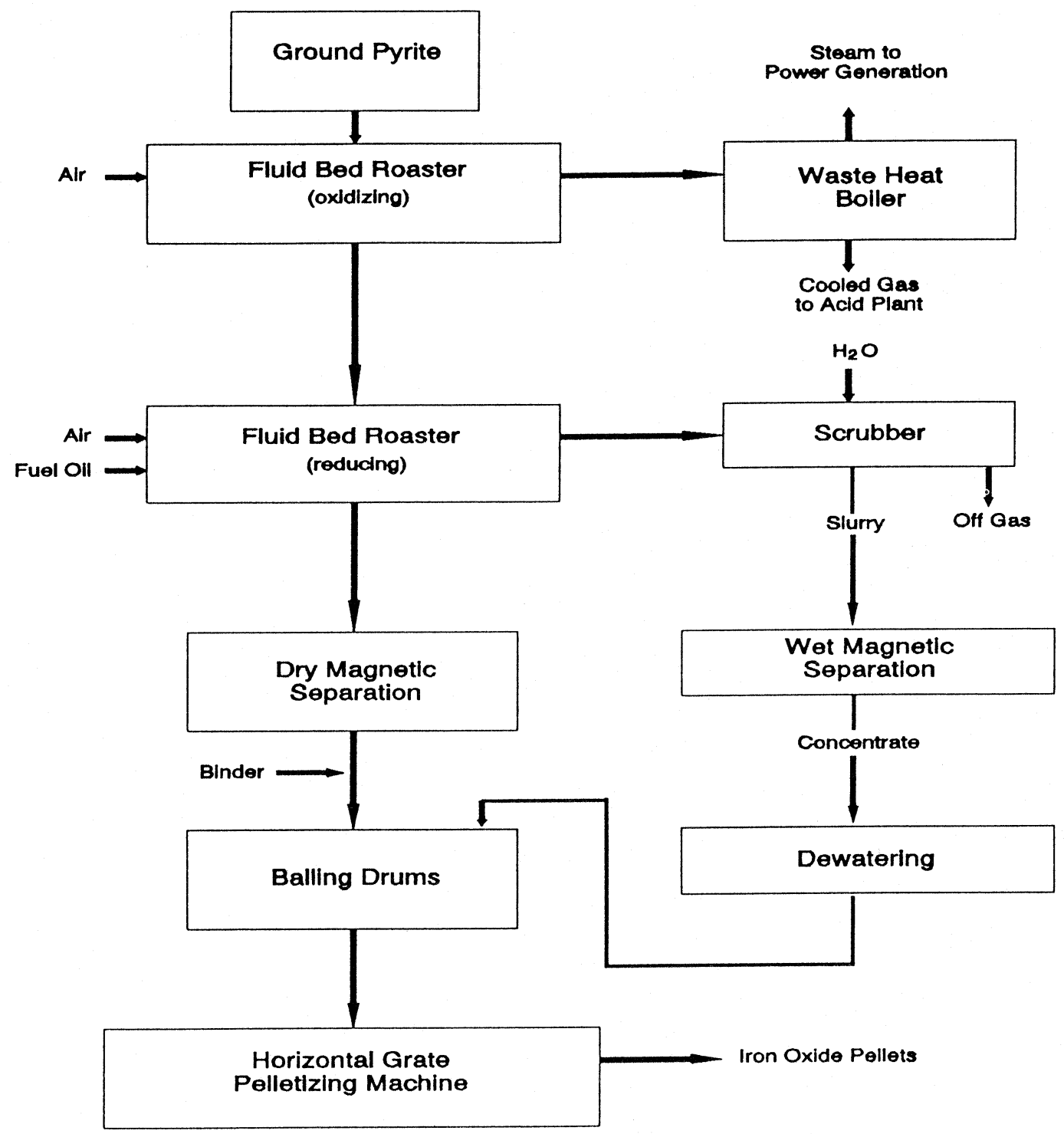

Figure. 4 The Montecatini Flowsheet 
570,000 kilowatt hours electricity per day. ${ }^{7}$ The process flowsheet is outlined in Figure $4 .{ }^{7}$

\section{3 EMERGING INDUSTRIES CREATED BY ENVIRONMENTAL LAW}

Environmental regulations are fostering the development of processes for treatment of a new class of materials, i.e., the treatment of materials containing a unique combination of metals. An example is the recovery of metal values from electroplating sludges containing copper, chromium, iron, nickel, zinc. It is estimated that over a million tons of electroplating waste sludge is generated annually in the United States.

Several United States and Canadian companies are now treating or are developing processes to treat electroplaing waste sludges, e.g., Recontec, Residuals Management, SOS. All of these companies use at least a portion of a process developed at Montana Tech by L.G. Twidwell and his graduate students, i.e., the Phosphate Process. A simplified flowsheet for the process is presented in Figure 5. The process is based on the selective separation of trivalent metals from divalent metals by phosphate precipitation.

The general sequence of treatment for a mixed metal sludge material containing copper, iron, chromium, cadmium, zinc and nickel is presented below :

- The sludge is leached in sulfuric acid at a pH of abous 1.5. Only about fifteen percent of the original solid remains and is a disposable residue.

- Copper is recovered from the leach solution by solvent extraction and electrowinning.

- Iron is next removed by precipitation of ferric phosphate with subsequent recovery of the phosphate reagent by caustic leaching the ferric phosphate. Ferric hydroxide is produced as a non-hazardous disporable residue.

- Chromium is next recovered by phosphate precipitation with subsequent recovery of chromium acid or sodium chromate from the chromium phosphate.

- Cadmium is recovered by cementation using zinc powder.

- Zinc is recovered by solvent extraction and electrowinning.

- Nickel is subsequently recovered as nickel hydroxide or nickel carbonate.

One of the characteristic features of the process is the selective recovery of iron and chromium from the divalent metals copper, zinc and nickel. Also, the phosphate precipitates are excellent filtering materials (similar to jarosites) that are not contaminated by adsorbed divalent metals. ${ }^{8}$

\section{4 PROCESSING STRATEGIES FOR FUTURE OPERATIONS}

Despite their technical success, the processes cited here were not financial bonanzas. Indeed, neither Duisberger Kupferhutte, Lakeshore nor the Fallonica plant is listed in the current E\&MJ International Directory. Yet the basic philosophy of maximizing recovery and minimizing plant discharge will be a necessary part of future operations and will become a significant factor in plant and process design and in capital and operating costs. Economic evaluation of newly discovered properties will include early examination of alternative processing options and environmental effects will markedly affect process selection. Process planning will include concerted efforts to yield byproducts of those minerals and elements that are harmful to the environment.

\section{REFERENCES}

1. R. Madigan, The Mineral Industry-What Next ?-Part 4, AIMM Bulletin, No.4, (1984) 4.

2. W. A. Griffith, et al, Development of the Roast-Leach-Electrowin Process for Lakeshore, J. 


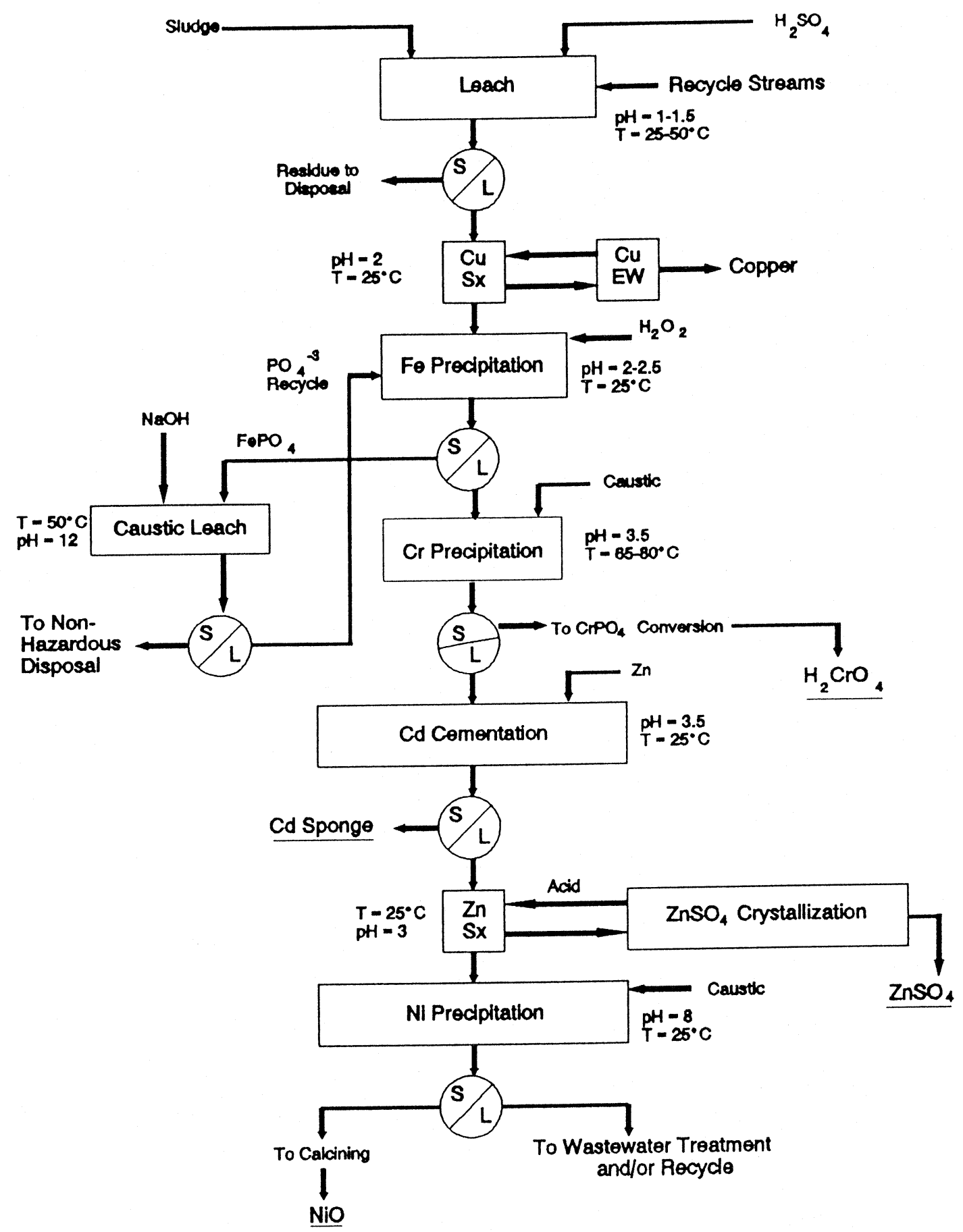

The Phosphate Process

Figure. 5 The Phosphate Precipitation Process 
Metals, Feb. 1975, 17.

3. T.S.Jordan and W.A.Griffith, Utilizing Mineralogy in Process Development for Hecla's Lakeshore Project, Preprint 84-93, AIME Ann. Mtng. (1984).

4. V. Ramachandran, ASARCO, Inc., Personal Colmunication (1991).

5. W. Teworte, The Duisburger Kupferhutte, Company Pub.1957.

6. F. Habashi, The Recovery Empire Built on Fool's Gold, Eng. \& Mining J., Dec. 1969, 59.

7. U. Colombo and G. Sironi, Pelletizing of Pyrite Ash by Montecatini Method, Demir Celik (Turkish), 16, No. 4, (1967) 117.

8. L. Twidwell, D. Dahnke, S. McGrath, Detoxification and Metal Recovery from Metal Finishing Sludge materials, Innovative Hazardous Waste Treatment Technology Series, Physical/Chemical Processes, Technomic, (1990) 55 